\title{
12. A Cytogenetic Assessment on the Origin of the Gold-fish
}

\author{
By Yoshio OJIma, Takayoshi UedA, and Toshitaka NARIKAWA \\ Department of Biology, Faculty of Science, \\ Kwansei Gakuin University, Nishinomiya
}

(Communicated by Sajiro Makino, M. J. A., Feb. 13, 1978)

We can find in some older literatures a record regarding that a certain prototypic variety of the gold-fish had appeared in the southern part of China about sixteen hundred years ago. The Wakin, a most primitive variety of the Japanese gold-fish, was said to be transported from China in 1502. One hundred years later (1611) it was introduced to Europe. It is almost impossible experimentally to produce by breeding the Wakin-type gold-fish from various varieties of the Funa (Carassius auratus). Inversely, varieties of the Funa could be produced experimentally through the segregation in breeding of various strains of the gold-fish. Cytogenetic investigations of hybrids between Funa and gold-fish, gold-fish and Carp, and Carp and Funa have yielded evidence to show that it is quite natural to look for the ancestor of the gold-fish in one of varieties in the Funa. To our present knowledge, it is difficult to obtain both genetically and cytologically conclusive evidence on the origin of the gold-fish, because relevant research data on Chinese Funa varieties are unfortunately lacking. The problem has remained to be explored in the future study.

The present study was undertaken in an aim to deal cytogenetically with the origin of the gold-fish, on the basis of comparative investigations of chromosomes of the gold-fish and Funa varieties from Japan, use being made of the current C-banding technique.

Materials and methods. Fig. 1 is a systematic tree which shows an evolutional process from the Funa to varieties of the gold-fish (After Matsui 1934). Solid lines indicate the product by mutation, and the dotted lines by cross-breeding.

Two females and 6 males of the Wakin (Japanese Golden); 5 females and 4 males of the Ryukin (Fringetail); 2 females and 1 male of the Oranda-Shishigashira (Dutch Lionhead); 3 females and 5 males of the Aka-Demekin (Red Telescope Eye) ; 2 males of the KyaricoDemekin (Calico Telescope Eye); 12 females and 16 males of the Kuro-Demekin (Black Telescope Eye) ; 6 females and 3 males of the Chotengan (Celestial) ; 4 females and 2 males of the Ranchu (Buffalohead) ; 3 females and 5 males of the Azuma-Nishiki (Dutch Calico); 
4 females and 6 males of the Shubunkin (Red Marked Calioc); 6 females and 4 males of the Comet; 3 females and 3 males of the Chunshu-yui (Pearlscale) ; 5 females and 4 males of the Ranuen-yui (Blue Marked Gold-fish); 2 females and 2 males of the Honto-yui; the Tancho (Redhead) ; 4 females and 5 males of the Honshuchu-yui (Red Velvetyball) furnished materials for the present chromosome studies. In almost all varieties herein dealt with the direct preparations from the kidney tissue were made with satisfactory results. The Giemsa C-banding technique was applied to them in order to supplement chromosome analysis.

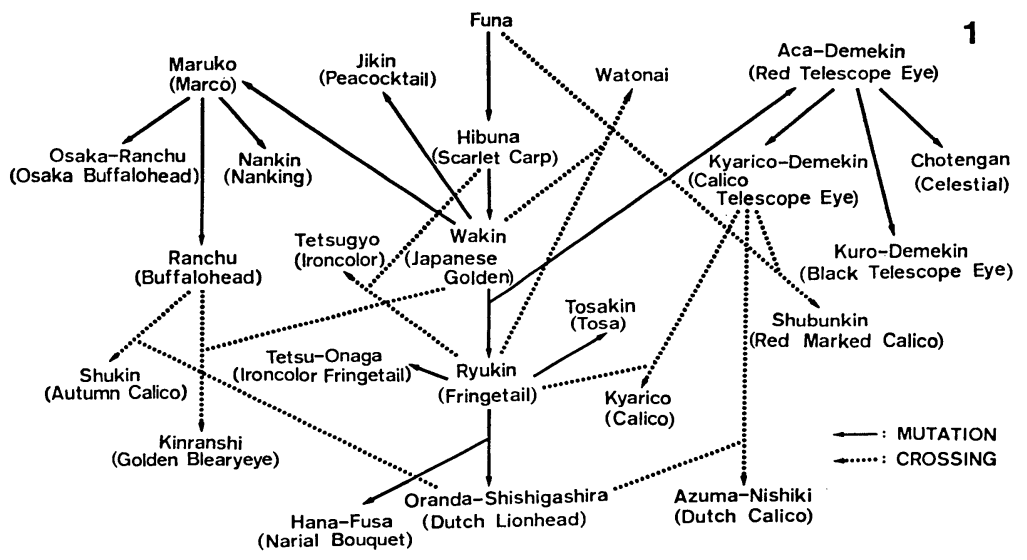

Fig. 1. Lineage diagram showing evolutional process of Japanese gold-fish varieties.

Results and discussion. In 1966 Ojima et al. studied the somatic chromosomes of the Gengorobuna (Carassius auratus cuvieri) and the gold-fish including the Wakin and the Ryukin, and showed that the somatic cells showed at metaphase 100 chromosomes as a diploid number. In all varieties studied the complement consisted of 6 pairs of metacentrics, 18 pairs of submetacentrics, and 26 pairs of telo- or subtelocentrics in both sexes. No polymorphic variation was observed in them, though such a feature was reported in meiotic chromosomes among varieties due to the occurrence of univalent elements (Makino 1941). Referring to the results of karyotype studies in Funa-varieties (Ueda and Ojima 1978), it is apparent that the chromosomes of the gold-fish varieties were fairly identical both numerically and morphologically with those of the Funa, the demarcation between them being quite impossible. Ueda and Ojima (1978) investigated comparatively the C-banding patterns of chromosomes in five subspecies of the Funa (Carassius auratus), and reported that the Ginbuna ( $C$. a. langsdorfii) which is the gynogenetic fish with triploid chromo- 
somes, was noted by carrying a pair of markers characterized by outstanding C-bands on the short arms of the second largest submetacentrics. In the Kinbuna ( $C$. $a$. subsp.), there were two such markers in the female while one in the male. The markers as found

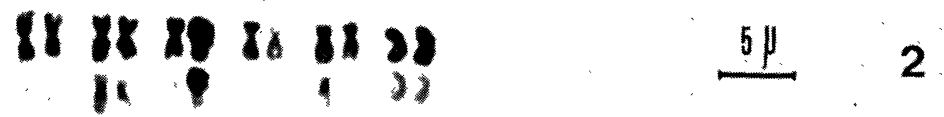

$$
\begin{aligned}
& \text { il II II iो || || || } \\
& \text {, है। } \\
& 148141 \text { 18 } 48
\end{aligned}
$$

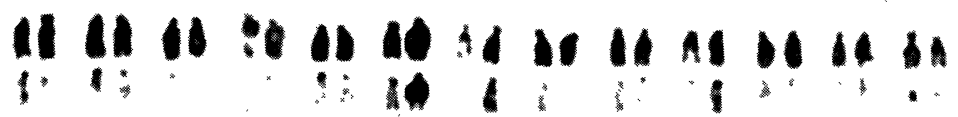

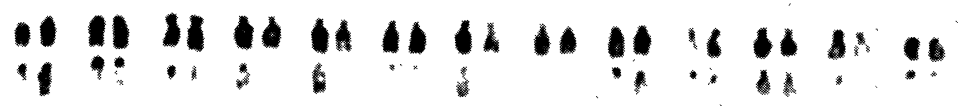

$$
\begin{aligned}
& \text { 18 I1 I1 XI1 }
\end{aligned}
$$

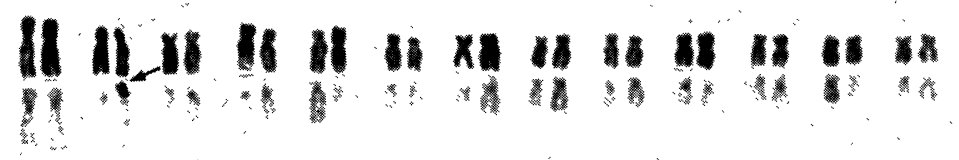

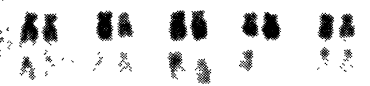

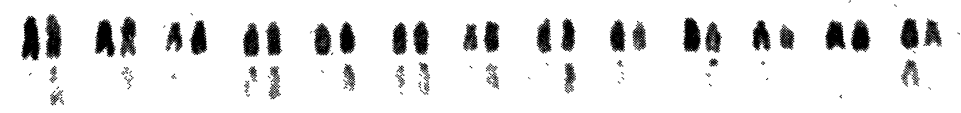

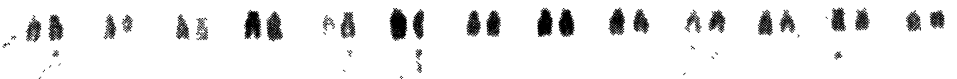

Figs. 2-3. 2: C-banding karyotype of the female of all varieties in gold-fish (the lower row). The arrows denote two large submetacentrics having intensely C-banded short arms. 3: C-banding karyotype of the male of all varieties in gold-fish and the female of Shubunkin and Comet (the lower row). The arrow denotes one large submetacentrics having intensely Cbanded short arms. 
in the Kinbuna (C.a. subsp.), however, could not be demonstrated in the other subspecies of the Funa such as the Gengorobuna (C. $a$. cuvieri), the Nigorobuna (C. a. grandoculis), and the Nagabuna ( $C$. a. buergeri). The present study demonstrated that all varieties of the gold-fish were characterized by $2 n, 100$ as well as by the same constitution as that reported by Ojima (1966). There was detected no remarkable sexual difference of the chromosomes among them.

Figs. 2 and 3 show the female and male karyotypes of varieties of the gold-fish here studied except the Comet and the Shubunkin. They were characterized by the second largest submetacentrics which had a pair of markers with deep C-bands on their short arms. Points to which special attention should be paid are the markers which were two in the female whereas one in the male. The above findings in the gold-fish varieties are nearly accordant with those in the Kinbuna $(C$. $a$. subsp.). Regarding so far the marker chromosomes in the Shubunkin in some detail, the picture is presented in Fig. 5. Referring to these figures it is evident that there is a pair of markers or one in the female, while one marker or none in the male (Figs. 2-5). We can theoretically consider on the basis of these findings that the Shubunkin would be originated from one of the following three reciprocal hybrids; (1) Funa subspecies such as $C$. a grandoculis, C. a. buergeri and $C$. a. cuvieri $\times$ Kyarico-Demekin; (2) C. a. subsp. $\times$ KyaricoDemekin; and (3) Wakin $\times$ Kyariko-Demekin. In some practical

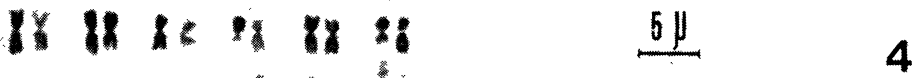

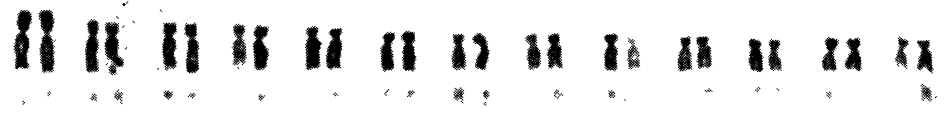

13 8. 1x 48 4:

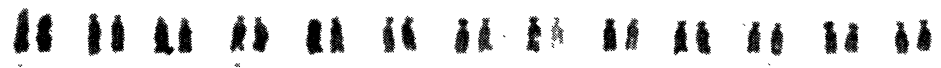 婉的

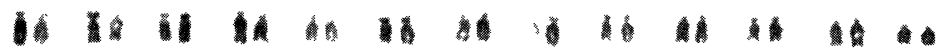

Fig. 4. C-banding karyotype of a male of Shubunkin and Comet (the lower row). 
breedings, a strain of the Shubunkin was obtained by such crossbreedings. Also, the Comet was known to obtain from a reciprocal hybridization between the Ryukin and the Funa.

As seen in Fig. 5, it appears that there occurs certain significant relation between the gold-fish and the Kinbuna ( $C$. $a$. subsp.), with regard to the differential marker chromosome. Regretting to say, cytogenetic data on the Chinese Funa varieties are insufficient for the above discussion, no statements having been allowed on this problem at present. Very probably, some kinds of subspecies of the Chinese Funa may carry the marker chromosomes as mentioned above which are differential and important for the evolution of the gold-fish. These emphasize the need for further investigations with the Chinese Funa varieties in order to inquire to the ancestor of the gold-fish cytogenetically.

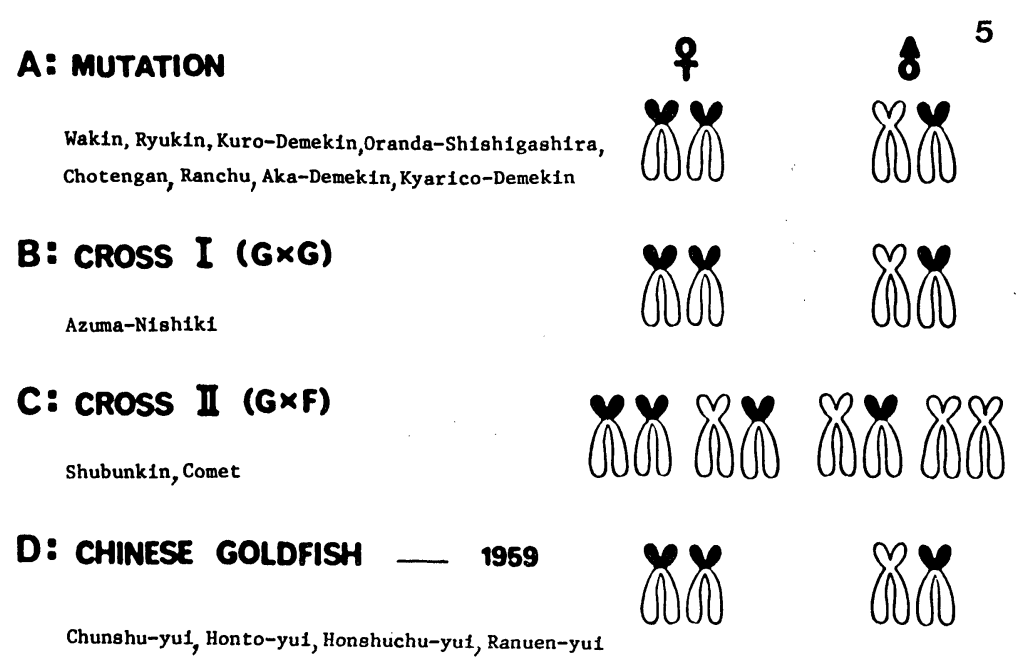

Fig. 5. Summarized illustrations of second submetacentric markers with C-banded short arms in varieties of gold-fish. G: Gold-fish. F: Funa.

Summary. In an aim to deal with the origin of the gold-fish, the chromosomes of fifteen varieties of the gold-fish are investigated in comparison with those of Funa subspecies according to the C-banding technique. The varieties excepting the Shubunkin and the Comet are characterized by the second largest submetacentrics chromosomes as markers carrying C-bands on their short arms, being two in the female and one in the male. The same feature is observed in the Kinbuna, a variety of Funa (C. a. subsp.). This seems to be an important picture for the assessment of the ancestor of the gold-fish.

We are very indebted to Dr. Sajiro Makino, M. J. A., Professor 
Emeritus, Hokkaido University, for improvement of the manuscript and revision of data.

\section{References}

Makino, S. (1941): A karyological study of gold-fish of Japan. Cytologia, 12, $96-111$.

Matsui, Y. (1934) : Genetical studies on gold-fish of Japan, I. On the varieties of gold-fish and variations in their external characteristics. J. Imp. Fish. Inst., 30, 1-36.

(1945) : Genetical studies of the Japanese gold-fish. 1, 2, 3, 4. Suisan Kenshu-Shi, 30, 1-82.

Ojima, Y., S. Hitotsumachi, and S. Makino (1966): Cytogenetic studies in lower vertebrates I. A preliminary report on the chromosomes of the Funa (Carassius auratus) and gold-fish. A revised study. Proc. Japan Acad., 42, 62-66.

Ueda, T., and Y. Ojima (1978): Differential chromosomal characteristics in the Funa subspecies (Carassius). Proc. Japan Acad., 54B, 283-288. 